\title{
ДИАГНОСТИКА И ОЦЕНИВАНИЕ ЗНАНИЙ, УМЕНИЙ И НАВЫКОВ НА ЗАНЯТИЯХ СПОРТИВНО-БАЛЬНОГО ТАНЦА (НА ПРИМЕРЕ СПОРТИВНО-БАЛЬНОГО КЛУБА «ЛАТИНСКИЙ КВАРТАЛ РЕУТОВ»)
}

\author{
Е. С. Сапрыкина \\ (Московский гуманитарный университет)
}

Аннотация: В статье описывается опыт работы спортивнобального клуба «Латинский Квартал Реутов» (2. Реутов, Московская область), в котором занятия бально-спортивными танцами проводятся под внешним и внутренним педагогическим контролем.

Ключевые слова: танцы; обучение танцу; спортивно-бальные танцы;; «Латинский Квартал Реутов»

\section{ASSESSING KNOWLEDGE AND SKILLS AT BALLROOM DANCE AND DANCESPORT CLASSES: THE QUARTIER LATIN REUTOV CLUB}

\author{
E. S. Saprykina \\ (Moscow University for the Humanities)
}

Abstract: The article examines the experience of teaching ballroom dancing and dancesport under both external and internal pedagogical control at the Quartier Latin Reutov club in the town of Reutov, Moscow Oblast.

Keywords: dancing; teaching dancing; ballroom dancing and dancesport; The Quartier Latin Reutov club

Занятия бально-спортивными танцами дают возможность всестороннего развития человека: это - сочетание физической нагрузки, с развитием музыкальности, грации, пластики, координации и коммуникативных навыков и повышение культуры общения. Хороший танцор обладает огромным количеством навыков. Поэтому одним из важных компонентов успешного образовательного процесса является способность танцора к научению, стремление получать как можно больше знаний, умений, навыков (Чистякова, 2008).

Занятия бальными танцами требуют серьезного подхода, т. к. этот вид спорта один из самых ресурсоемких. И, следовательно, и юные танцоры, и их родители стремятся получить максимальную отдачу. Следует 
отметить, популярность данного танцевального направления привела к высокой конкуренции среди исполнителей.

Занятия спортивно-бальными танцами требуют особого подхода. Танцору-бальнику необходимо освоить не только технику танца. Танцор должен слышать и чувствовать музыку, уметь перевоплощаться, вживаясь в тот или иной образ для передачи эмоций. При этом для занятий танцами необходима гибкость, сила, выносливость, что многократно усложняет задачу тренера, так как развитие силы зачастую ведет к снижению гибкости и наоборот. К тому же танцор должен обладать развитой памятью, быть дисциплинированным и спокойным, уравновешенным. Что может диссонировать с необходимостью побеждать, двигаться вперед и бороться на турнирах с другими танцорами.

Именно поэтому в нашей школе спортивно-бального клуба «Латинский Квартал Реутов» (Московская область) проводится входное тестирование, цель которого выявить способности ребенка к занятию бальными танцами. Мы считаем, что необходимо выявить сильные и слабые стороны ребенка. Это нужно для того, чтобы родители были готовы к тем или иным затратам всех видов ресурса, чтобы ожидания родителей не превосходили потенциальных возможностей ребенка. Входной тест включает в себя:

- тест на выносливость, гибкость, силу;

- тест на музыкальность;

- тест на способность к копированию и запоминанию новой информации;

- собеседование с психологом.

Во время входного тестирования ведется видеозапись, что позволяет в дальнейшем наглядно наблюдать за развитием танцора. По итогам собеседования формируются группы: «профессиональная» (конкурсные пары) и «любительская» (те, кто хочет танцевать исключительно для себя). Работа в команде с детьми, у которых аналогичные устремления психологически более комфортна для ребенка, позволяет создать нужный эмоциональный настрой и добиваться более качественного результата.

Профессиональная подготовка танцора нуждается в регулярной и точной оценке знаний, умений и навыков. Такая оценка позволяет понять, чего достиг танцор за определенный период обучения.

Традиционной формой внешнего контроля «качества обученности» в бальных танцах выступают танцевальные турниры. Соревнования проводятся регулярно, поэтому при желании и наличии возможностей можно ездить на турниры несколько раз в неделю. На этих мероприятиях ребенок набирает очки для перехода в следующий класс, получает кубки, медали, грамоты. Выездной турнир это - отличная возможность понять, 
чего достиг ребенок за тот или иной промежуток времени. Участие в турнирах является итоговой формой контроля.

Но помимо внешнего контроля необходим контроль внутренний. К формам внутреннего контроля можно отнести концерты, турниры внутри клуба. Такие мероприятия позволяю ребенку раскрыть свои способности в ситуации более спокойной, чем выездной турнир, но в то же время помогают выявить проблемные зоны той или иной танцевальной пары.

Диагностика и оценивание знаний, умений, навыков (ЗУН) является неотъемлемой частью всего процесса обучения: диагностика необходима для корректировки тренировочного процесса, составления плана дальнейших тренировок. Педагогу в процессе занятий с учащимися необходимо формировать у своих воспитанников навыки самооценки в соответствии с принятыми критериями оценки исполнительского мастерства (Рубинштейн, 2007; Учебно-методические ..., 2006).

Для карьерного роста танцору необходимо: развить волевые качества (такие как, выносливость, упорство в достижении цели и др.), профессиональные способности (гибкость, сила, координация движений, память, внимание, чувство ритма, эмоциональная отзывчивость на музыку и др.), приобрести исполнительские навыки. В связи с этим, система оценок должна быть объективной и включать в себя контроль за различными параметрами, при этом быть предельно прозрачной, чтобы эффективность работы мог оценить не только педагог, но и танцоры, родители. Регулярная оценка достижений не только на соревнованиях, но и внутри коллектива позволяет поддерживать стабильно высокий интерес детей к занятиям, что немаловажно, в условиях невысокой мотивации к занятиям у детей и подростков.

В танцевальном коллективе «Латинский Квартал Реутов» мы применяем следующую систему оценки качества обученности, которая состоит из нескольких модулей диагностики ЗУН:

1. Оценка теоретических знаний (проводится раз в месяц): проверяются знания движений и схем танцев в соответствии классом обучающихся детей, усвоение вариаций, а также правил поведения в зале и на конкурсах;

2. Проведение прогонов: исполнение каждой парой своей конкурсной программы. Это помогает определить уровень выносливости пары и ошибки в танце;

3. Творческий тест: дети составляют собственные вариации танцев, в соответствии со своим классом, оценивается оригинальность, музыкальность исполнения, общая эстетика композиции.

Все модули проводятся без предупреждения, что позволяет понять насколько ребенок усвоил информацию, полученную на занятиях. Надо 
отметить, в клубе постоянно ведется видео съемка, что позволяет наглядно разобрать ошибки каждого танцора, а также упрощает задачу тренера во время разбора ошибок. Ведь танец не только спортивная, но и творческая дисциплина, что повышает риск формирования субъективной оценки как парой пары, пары тренером, пары родителями, партнерами друг друга. Видео запись помогает избежать разногласий и споров.

Перечисленные выше методы контроля ЗУН помогают эффективно развивать каждую пару, повышая уровень танцевания каждой пары и уровень развития клуба. Используя входной, промежуточный и итоговый контроль и сопоставляя результаты диагностики тренер может понять, как строить дальнейшую работу с детьми и их родителями, что делает занятия более эффективными и полезными, снижая энерго- и ресурсозатраты каждой пары.

\section{СПИСОК ЛИТЕРАТУРЫ}

Рубштейн Н. (2007) «Что нужно знать, чтобы стать первым»: «Тренер». М. : Кручинин Л. Ю. 160 с.

Учебно-методические рекомендации по организации работы с целым классом (2006). М. : Шутиков Ю. Н. 136 с.

Чистякова, А. А. (2008) Диагностика и оценивание знаний, умений и навыков на занятиях по народному танцу в педагогическом колледже. // Психодидактика высшего и среднего образования. Часть II: Материалы седьмой международной научно-практической конференции. Барнаул : БГПУ. С. 223-225.

Сапрыкина Екатерина Сергеевна - студентка факультета культуры и искусства направления «хореографическое искусство» Московского гуманитарного университета. Адрес: 111395, Россия, г. Москва, ул. Юности, д. 5. Тел.: 7 (499) 374-59-40. Эл. адрес: 3730014@mail.ru

Saprykina Ekaterina Sergeyevna, Undergraduate student majoring in Choreography, Department of Culture and Art, Moscow University for the Humanities. Postal address: 5 Yunosti St., Moscow, Russian Federation 111395. Tel.:+7 (499) 374-59-40. E-mail: 3730014@mail.ru 